\title{
Measurement of Low Magnesium Concentration in Aqueous Solution
}

\author{
Mahmoud Naseri, ${ }^{1}$ Amir Reza Sadrolhosseini, ${ }^{2 *}$ \\ Yap Wing Fen, ${ }^{3}$ and Mohd Adzir Mahdi ${ }^{4}$
${ }^{1}$ Department of Physics, Faculty of Science, Malayer University, Malayer, Iran
${ }^{2}$ Functional Device Laboratory, Institute of Advanced Technology, Universiti Putra Malaysia, 43400UPM, Serdang, Selangor, Malaysia.
${ }^{3}$ Department of Physics, Faculty of Science, Universiti Putra Malaysia, 43400UPM, Serdang, Selangor, Malaysia
${ }^{4}$ Department of Computer and Communications System Engineering, Faculty of Engineering, Universiti Putra Malaysia, 43400UPM, Serdang, Selangor, Malaysia

(Received December 6, 2017; accepted March 2, 2018)

Keywords: Mg, surface plasmon resonance, nickel-ferrite nanoparticle, polypyrrole

Magnesium is an alkaline earth metal that is found in some types of biological sample. One of the responsibilities of medical biological laboratories is the measurement of magnesium. In this study, the metal layer of the surface plasmon resonance sensor was improved using polypyrrole-chitosan/nickel-ferrite nanoparticles to enhance the sensitivity and selectivity of the sensor. The composite layer of polypyrrole-chitosan/nickel-ferrite nanoparticles was prepared by the electrochemical method on a gold-coated glass slide. The measurements were conducted at room temperature with different concentrations of magnesium. In order to determine the selectivity of the sensor, its response was compared with the results obtained in the presence of sodium and calcium ions. The sensitivity limit of the sensor was about $0.1 \mathrm{mg} / \mathrm{L}$, and the response time of the sensing layer was about $350 \mathrm{~s}$.

\section{Introduction}

Magnesium $(\mathrm{Mg})$ is present in biological tissues, ${ }^{(1)}$ the environment, and industrial materials. $^{(2)} \mathrm{Mg}$ reacts readily with most alkalis and many organic chemicals, such as hydrocarbons, aldehydes, phenols, amines, and some natural oils. ${ }^{(3,4)} \mathrm{Mg}$ can be used as a catalyst, for photoengraved plates in the printing industry, and for the reduction and purification of sulfur from iron and iron alloys. It can also be used in the dehalogenization process in some chemical reactions to initiate organic reactions, and it serves as a reducing agent for producing high-purity uranium and for flashbulb photography. ${ }^{(5)}$ Highly sensitive analytical methods are usually used to detect and measure magnesium in water, food, blood, fuel, oil, and agricultural products. These analytical methods include atomic absorption spectroscopy, ${ }^{(6-9)}$ atomic emission spectroscopy, ${ }^{(10)}$ inductively coupled plasma emission spectroscopy, ${ }^{(11-15)}$

*Corresponding author: e-mail: amir.reza@upm.edu.my http://dx.doi.org/10.18494/SAM.2018.1837 
spectrophotometric simultaneous determination of magnesium based on the classic least-squares method, ${ }^{(16)}$ the colorimetric technique, ${ }^{(17)}$ and flame atomic absorption spectrometry. ${ }^{(18)}$

Some of the limitations associated with the methods listed above are the chemical knowledge required to utilize them, the high cost of the instruments, the need to calibrate the devices before use, their lack of portability, and their nonlinear calibration curves. The surface plasmon resonance (SPR) technique is a versatile, accurate, and portable method that can detect heavy metals, biological components, and toxic chemicals. ${ }^{(19)}$ The SPR technique is an optical method that is based on changes in the refractive index of the sensing layer during chemical binding or the association process. ${ }^{(20)}$

In order to improve the sensitivity, selectivity, and response time of SPR sensors in detecting $\mathrm{Mg}$, the gold layer must be modified using a special chemical layer, such as a polymer, or a conductive polymer. ${ }^{(21)}$ Polypyrrole-chitosan, ${ }^{(22,23)}$ nickel nanoparticles, ${ }^{(24-26)}$ and ferrite nanoparticles have the potential to detect toxic chemicals (heavy metals) and biological molecules. ${ }^{(27-29)}$ Polypyrrole, chitosan and nickel ferrite nanoparticles altogether can capture the metal elements. In a previous research, ${ }^{(30)}$ the nickel-ferrite nanoparticles were magnetized, and they could absorb paramagnetic heavy metal such as Ni, Fe, and Co. In previous work, the effect of nickel ferrite nanoparticles was used to detect the ferromagnetic, paramagnetic, and diamagnetic heavy metals. Hence, the sensitivity and selectivity increased. ${ }^{(30)}$

In this study, the concentrations of magnesium, potassium and sodium ions were measured by the SPR technique in aqueous solution. The gold layer was modified using PPy-Chi/ $\mathrm{NiFe}_{2} \mathrm{O}_{4}$-NP to improve the selectivity and sensitivity of the sensor. The sensitivity and selectivity of the SPR sensor were achieved through comparison of the results of the detection of magnesium, sodium and potassium ions in aqueous solution.

\section{Materials and Methods}

\subsection{Preparation of heavy metal ions}

For the preparation of the metal ions including $\mathrm{Mg}^{2+}, \mathrm{Na}^{+}$, and $\mathrm{K}^{+}$in aqueous solution, $1 \mathrm{~g}$ of $\mathrm{MgSO}_{4}, \mathrm{Na}_{2} \mathrm{SO}_{4}$, and $\mathrm{K}_{2} \mathrm{SO}_{4}$ were each dissolved in 1 liter of distilled deionized water (DDW) to produce $1000 \mathrm{ppm}$ solutions. Then, other concentrations, including $0.1,0.5,1,5,10,25,50$, and $100 \mathrm{ppm}$, were prepared by systematic dilution of the $1000 \mathrm{ppm}$ solutions.

\subsection{Preparation of $\mathrm{NiFe}_{2} \mathrm{O}_{4}$}

An aqueous solution of polyvinylpyrrolidone (PVP) was prepared by dissolving $3.5 \mathrm{~g}$ of polymer in $100 \mathrm{ml}$ of DDW at $343 \mathrm{~K}$. Then, $0.2 \mathrm{M}$ of iron nitrate and $0.1 \mathrm{M}$ of nickel nitrate $(\mathrm{Fe}: \mathrm{Ni}=2: 1)$ were placed in the polymer solution that was stirred for $2 \mathrm{~h}$ using a magnetic stirrer. At the end of the $2 \mathrm{~h}$ period, a colorless, transparent solution was obtained. The solution was poured into a glass Petri dish and heated in an oven at $353 \mathrm{~K}$ for $24 \mathrm{~h}$ to evaporate the water. The dried orange solid that remained was crushed and ground for $20 \mathrm{~min}$ in a mortar to form powder. The calcination of the powder was conducted at different calcination temperatures for $3 \mathrm{~h}$ to decompose the organic compounds and crystallize the nanocrystals. ${ }^{(31)}$ Magnetic characterization of the nickel ferrite nanoparticles was performed using a vibrating sample 
magnetometer (VSM) (Lake Shore 4700) at room temperature with a maximum magnetic field of $15 \mathrm{kOe} .^{(30)}$

\subsection{Preparation of PPy-Chi/NiFe $\mathrm{O}_{4}-\mathrm{NP}$ layer}

The gold-coated glass slide was prepared with a sputter coating of $49 \mathrm{~nm}$ thickness prior to the electrodeposition of the $\mathrm{PPy}-\mathrm{Chi} / \mathrm{NiFe}_{2} \mathrm{O}_{4}-\mathrm{NP}{ }^{(30)}$ composite layer.

The PPy-Chi/ $\mathrm{NiFe}_{2} \mathrm{O}_{4}-\mathrm{NP}$ composite layers were fabricated by electrochemical polymerization of distilled pyrrole in the presence of $\mathrm{NiFe}_{2} \mathrm{O}_{4}$ nanoparticles. $\mathrm{NiFe}_{2} \mathrm{O}_{4}$ nanoparticles were dissolved in the mixture of the sodium dodecylbenzensulfonate (SDBS) and DDW. $\mathrm{NiFe}_{2} \mathrm{O}_{4}$ nanoparticles with a $0.03 \%$ weight ratio to the pyrrole monomer were dispersed in a SDBS solution, and were sonicated for $8 \mathrm{~h}$ to disaggregate any nanoparticle bundles. The ratio of $\mathrm{NiFe}_{2} \mathrm{O}_{4}$ nanoparticles to SDBS was 1:10.

Prior to the electrodeposition, $0.7 \% \mathrm{w} / \mathrm{v}$ of chitosan was dissolved in acetic acid at room temperature. Then the mixture of $\mathrm{NiFe}_{2} \mathrm{O}_{4}$ - NPs and SDBS solution was dispersed in the chitosan solution and while the solution was mechanically stirred, the pyrrole was added to the mixture. The PPy-Chi/ $\mathrm{NiFe}_{2} \mathrm{O}_{4}-\mathrm{NP}$ premixed solution was electropolymerized at +1.2 $\mathrm{V}$ in a three-electrode electrochemical cell. A gold-coated microscope glass slide electrode was used as a working electrodes. A graphite rod and a saturated calomel electrode were used as the counter and reference electrode, respectively. The electrodeposition of layers was carried out at room temperature using an electrochemical instrument (VersaSTAT 3, Ametek, Princeton Applied Research), and the deposition time was changed from 68 to $510 \mathrm{~s}$ to control the thickness of PPy-Chi/ $\mathrm{NiFe}_{2} \mathrm{O}_{4}-\mathrm{NP}$ nanocomposite. The final PPy-Chi/ $\mathrm{NiFe}_{2} \mathrm{O}_{4}-\mathrm{NP}$ thin layer was washed with water and methanol to remove the electrolyte solution and dried under a vacuum at $23{ }^{\circ} \mathrm{C}$ for $12 \mathrm{~h}$. The $\mathrm{PPy}-\mathrm{Chi} / \mathrm{NiFe}_{2} \mathrm{O}_{4}-\mathrm{NP}$ layers were characterized by field emission scanning electron microscopy (FE-SEM, Hitachi, SU8000 Series), and energy dispersive spectroscopy (EDX, Oxford Instruments, X-Max).

\subsection{SPR test}

Figure 1 shows the SPR setup. The SPR setup was arranged with a high-index prism based on the Kretschmann configuration. ${ }^{(20-22)}$ A high-index prism (ZF52, Foctek) was used to generate the SPR signals, and the aqueous solution flowed into the tank that was attached to the prism. The sensing layer was attached to the prism using liquid index gel. The surface plasmon waves were excited by the transverse mode (TM mode) of a He-Ne laser $(632.8 \mathrm{~nm}, 5 \mathrm{mw})$ after passing through the polarizer. The SPR signals were registered using a silicon detector to draw the sensogram. The experiment was repeated 10 times for each ion. The SPR signals were analyzed by the matrix method based on the Fresnel equation to obtain the shift of the resonance angle. ${ }^{(21,22)}$

\section{Results and Discussion}




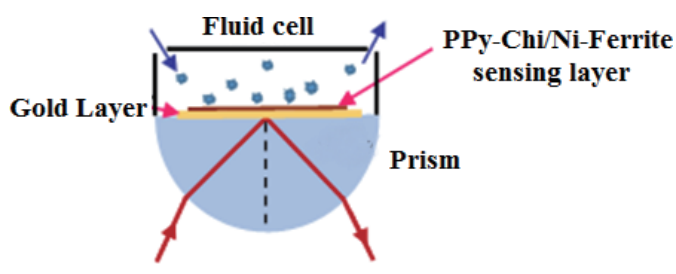

Fig. 1. (Color online) Sensing layer attached to the high-index prism from an uncoated microscope glass slide. The ions were bound to the sensing layer ( $\mathrm{PPy}-\mathrm{Chi} / \mathrm{NiFe}_{3} \mathrm{O}_{4}-\mathrm{NP}$ composite).

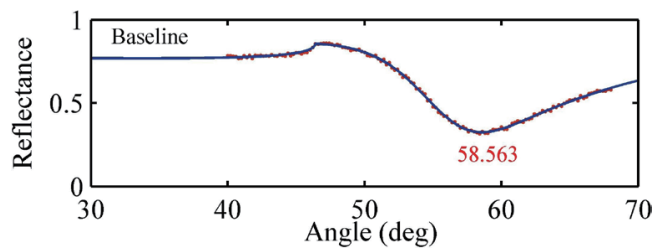

(a)

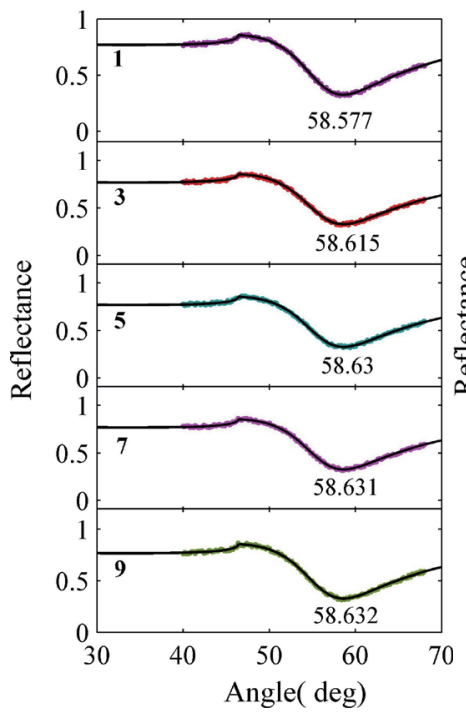

(b)

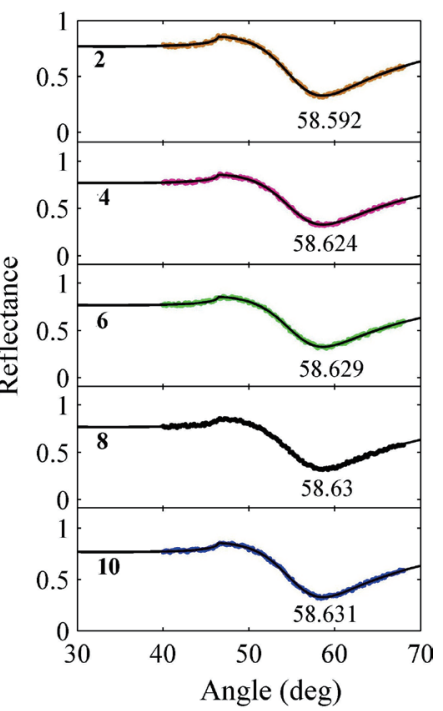

Fig. 2. (Color online) (a) SPR signal at the baseline and (b) SPR signal corresponding to the detection of Mg ions at a concentration of $0.1 \mathrm{ppm}$. The SPR signals were presented at each experiment from the first to 10th experiments.

Figure 2 shows the baseline SPR signal that was obtained in the presence of DDW. The thickness and the refractive index of the PPy-Chi/ $\mathrm{NiFe}_{2} \mathrm{O}_{4}-\mathrm{NP}$ thin layer were $25.5 \mathrm{~nm}$ and $1.6342+0.166 i$, respectively. The resonance angle of the SPR signal at the baseline was $58.563^{\circ}$. Afterwards, solutions containing different concentrations of $\mathrm{Mg}$ ions, i.e., 0.1, 0.5, 1, 5, 10, 25, 50 , and $100 \mathrm{ppm}$, were introduced separately into the fluid tank to conduct the experiments and register the SPR signals. In order to obtain the sensogram, the variation of resonance angle with time should be registered. In this study, the experiment was repeated ten times for each sample. Figure 2(b) shows the SPR signals belong to the lowest concentration of Mg ions (0.1 ppm) during the binding of $\mathrm{Mg}$ ions on the surface of the sensing layer. Figure 2(b) shows the SPR signals from the first experiment to the 10th experiment. The resonance angles were achieved from SPR signals at different times. $\mathrm{Mg}$ was bound on the surface of the sensing layer, and the angle of resonance was shifted from $58.577^{\circ}$ to $58.632^{\circ}$. The experiment was repeated for the other concentrations of $\mathrm{Mg}$ ions to obtain the associated SPR signals. The variation in the shifts of the resonance angles with time is shown in Fig. 3. The sensogram shows that the variation of the resonance angle increased as the time and the concentration of the $\mathrm{Mg}$ ions increased.

The plotted points in Fig. 3 are the experimental data that were derived by subtracting 


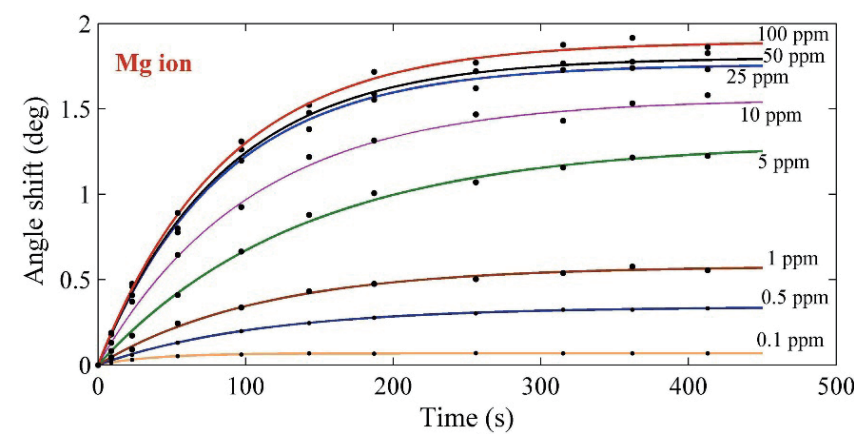

(a)

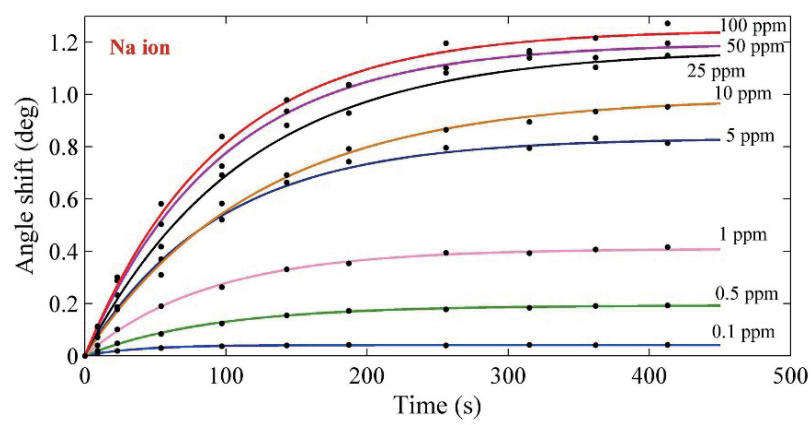

(b)

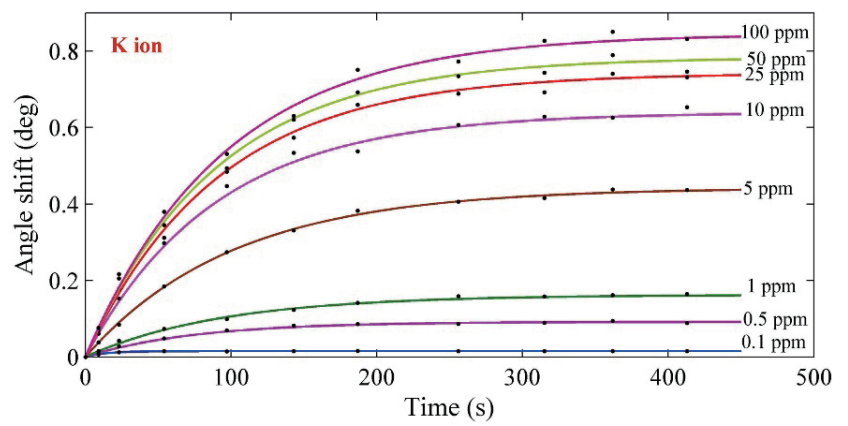

(c)

Fig. 3. (Color online) Variation in the shift of the resonance angle versus time: (a) $\mathrm{Mg}$, (b) $\mathrm{Na}$, and (c) $\mathrm{K}$ ions.

the resonance angle at each time from the resonance angle at the baseline. The shift of the resonance angle was due to the ions being bound on the surface of the PPy-Chi/ $/ \mathrm{NiFe}_{2} \mathrm{O}_{4}-\mathrm{NPs}$ in the association process. The solid lines show results calculated using Langmuir's first-order adsorption model $\left\{\Delta \theta=\Delta \theta_{s a t}\left[1-\exp \left(-k_{a} t\right)\right]\right\},{ }^{(32,33)}$ and they fitted well with the experimental data. The terminal value of the shift of the resonance angle $\left(\Delta \theta_{\text {sat }}\right)$, the rate constant $\left(k_{a}\right)$, and the response time of the sensor were calculated for each concentration of $\mathrm{Mg}, \mathrm{Na}$, and $\mathrm{K}$ ions using the sensogram based on Langmuir's first-order adsorption model. As a result, the terminal value was achieved at $350 \mathrm{~s}$. Consequently, the response time of the sensor is $350 \mathrm{~s}$. The numerical values are listed in Table 1. Figure 4 shows the variation of the shift in the resonance angle at the terminal value $\left(\Delta \theta_{s a t}\right)$ versus the concentration of ions $(C)$, and the solid lines were calculated using the Langmuir equation, $\Delta \theta_{s a t}=\frac{\Delta \theta_{\max } \times C \times K}{1+K C}$. (34) The terminal value is a function of the concentration of ions $(C)$, the maximum shift of the resonance angle $\left(\Delta \theta_{\max }\right)$ and the affinity constant $(K)$. In order to determine $\Delta \theta_{\max }$, and $K$, the minimum square-root method was used to fit the Langmuir equation to the experimental data. The numerical values of the parameters are provided in Table 1.

The concentrations of $\mathrm{Mg}, \mathrm{Na}$, and $\mathrm{K}$ ions that were attached to the PPy-Chi/ $\mathrm{NiFe}_{2} \mathrm{O}_{4}-\mathrm{NP}$ composite layer were measured by inductively coupled plasma mass spectroscopy (ICP-MS) after using 5 ppm solutions. The sensing layers were immersed in $\mathrm{HNO}_{3}(2 \mathrm{M})$ separately, and the ions were released from the layer to the liquids. The concentrations of the released ions were measured with an accuracy of about $0.001 \mathrm{mg} / \mathrm{L}$, and the results are presented in Table 2 . 
Table 1

Terminal value of the shift of the resonance angle $\left(\Delta \theta_{\text {sat }}\right)$, the maximum shift of the resonance angle $\left(\Delta \theta_{\max }\right)$, and the affinity constant $(K)$ for $\mathrm{Mg}, \mathrm{Na}$, and $\mathrm{K}$ ions.

\begin{tabular}{cccc}
\hline $\begin{array}{c}\text { Concentration } \\
(\mathrm{ppm})\end{array}$ & $\mathrm{Mg}$ & $\mathrm{Na}$ & $\mathrm{K}$ \\
$\Delta \theta_{\text {sat }}$ & $\Delta \theta_{\text {sat }}$ & $\Delta \theta_{\text {sat }}$ \\
\hline 0.1 & 0.076 & 0.044 & 0.02 \\
0.5 & 0.33 & 0.19 & 0.092 \\
1 & 0.56 & 0.4 & 0.16 \\
5 & 1.23 & 0.81 & 0.43 \\
10 & 1.51 & 0.95 & 0.62 \\
25 & 1.70 & 1.13 & 0.72 \\
50 & 1.74 & 1.16 & 0.76 \\
100 & 1.83 & 1.21 & 0.82 \\
$\Delta \theta_{\max }$ & 1.842 & 1.232 & 0.8336 \\
$K$ & 0.4233 & 0.3717 & 0.2358 \\
\hline
\end{tabular}

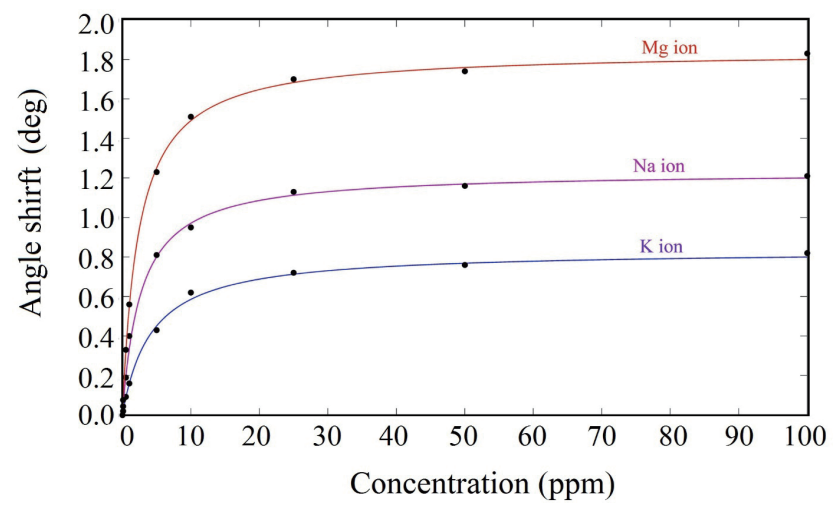

Fig. 4. (Color online) Variation in the shift of the resonance angle with the concentration of $\mathrm{Mg}$, $\mathrm{Na}$, and $\mathrm{K}$ ions during bonding with the sensing layer.

Table 2

Concentration of ions before and after the experiments.

\begin{tabular}{ccccc}
\hline Sample & $\begin{array}{c}\text { Concentration of ions in solution } \\
\text { before experiment } \\
(\mathrm{ppm})\end{array}$ & $\begin{array}{c}\text { Concentration of ions in } \\
\text { solution after experiment } \\
(\mathrm{ppm})\end{array}$ & $\begin{array}{c}\text { Concentration of ions released } \\
\text { from sensing layer in } \mathrm{HNO}_{3} \\
(\mathrm{ppm})\end{array}$ & $E(\%)$ \\
\hline $\mathrm{Mg}$ & 5.003 & 0.683 & 4.18 & 86.3 \\
$\mathrm{Na}$ & 4.985 & 1.045 & 3.74 & 79.03 \\
$\mathrm{~K}$ & 5.012 & 1.862 & 2.96 & 62.8 \\
\hline
\end{tabular}

If $C_{0}$ and $C_{f}$ are considered to be the concentrations of the ions in the initial and final solutions, respectively, the degree of adsorption of $\mathrm{Mg}, \mathrm{Na}$, and $\mathrm{K}$ ions on the sensing layer is estimated as

$$
E=100 \times\left(C_{0}-C_{f}\right) / C_{0} .
$$

The Mg ions showed the maximum degree of adsorption. Consequently, the variation of the shift of the resonance angle for the $\mathrm{Mg}$ ions was the largest, and the variation of the shift of the resonance angle for $\mathrm{K}$ ions was the smallest. 
The PPy-Chi/ $\mathrm{NiFe}_{2} \mathrm{O}_{4}$-NPs composite layer contained chitosan and $\mathrm{NiFe}_{2} \mathrm{O}_{4}-\mathrm{NP}$. The main elements for the absorption of $\mathrm{Mg}$ ion was chitosan and the magnetic properties of $\mathrm{NiFe}_{2} \mathrm{O}_{4}$ NP. Chitosan was poly(b-1-4)-2-amino-2-deoxy-D-glucopyranose, obtained by a full alkaline $N$-deactylation of chitin. The amino $(-\mathrm{NH} 2)$ and hydroxyl groups $(-\mathrm{OH})$ on the chitosan chains can adsorb metal ions, and the affinity of chitosan corresponds to the metal ions. ${ }^{(35)}$ Therefore, the amino group of chitosan is the principal group involved in binding metal ions, and it is generally accepted that metal ions are immobilized on chitosan via four amino groups in the square-planar geometry. ${ }^{(36)}$

$\mathrm{NiFe}_{2} \mathrm{O}_{4}-\mathrm{NP}$ exhibited ferromagnetic behaviour and it generated a magnetic field around the thin layer. This magnetic field induced a magnetic moment on $\mathrm{Mg}$ ions near the layer, which adsorbed the $\mathrm{Mg}$ ions. Consequently, the magnetic nanoparticles assisted the chitosan to adsorb and bind the $\mathrm{Mg}$ ions to the $\mathrm{PPy}-\mathrm{Chi} / \mathrm{NiFe}_{2} \mathrm{O}_{4}-\mathrm{NP}$ composite layer, and when the $\mathrm{Mg}$ ions bound to the sensing layer, $\mathrm{NiFe}_{2} \mathrm{O}_{4}-\mathrm{NP}$ caused the sensing layer to hold the ions and the terminal value was rapidly achieved.

\section{Conclusion}

The polypyrrole-chitosan/nickel-ferrite-nanoparticle composite was used to detect and measure the concentrations of $\mathrm{Mg}, \mathrm{N}$, and $\mathrm{K}$ ions in aqueous solutions. The sensing layer was prepared by the electrochemical method. The thickness of the sensing layer was $49 \mathrm{~nm}$, and it could detect $\mathrm{Mg}$ ions with greater sensitivity than the $\mathrm{Na}$ and $\mathrm{K}$ ions. The concentration of $\mathrm{Mg}$ ions that were bound on the sensing layer was higher than those of other ions. The detection limit of the sensor for $\mathrm{Mg}$ ions was about $0.1 \mathrm{ppm}$, and the shifts of resonance angle for detecting $\mathrm{Mg}, \mathrm{Na}$, and $\mathrm{K}$ were $1.842^{\circ}, 1.232^{\circ}$, and $0.8336^{\circ}$ respectively. Hence, the sensing layer was highly sensitive for detecting $\mathrm{Mg}$ ion.

\section{References}

1 C. Mason: Biology of Freshwater Pollution (Pearson Harlow, London, 2002).

2 R. W. Raiswell: Environmental Chemistry-The Earth-Air-Water Factory (Edward Arnold, London, 1980).

3 P. Enghag: Encyclopedia of the Elements-Technical Data, History, Processing, Applications. (Wiley-VCH, Wainheim, 2004).

4 F. Ramade: Ecotoxicology (Wiley, Chichester, UK, 1987).

5 LENNTECH: http://www.lenntech.com/periodic/elements/mg.htm\#ixzz3zv2GJv6C (accessed January 2017).

6 A. Jesus, A. V. Zmozinski, J. A. Barbara, M. G. R. Vale, and M. M. Silva: Energy Fuels 24 (2010) 2109.

7 R. S. Amais, E. E. Garcia, M. R. Monteiro, and J. A. Nóbrega: Fuel 93 (2012) 167.

8 F. H. Lyra, M. T. W. D. Carneiro, G. P. Brandão, H. M. Pessoa, and E. V. Castro: Microchem. J. 96 (2010) 180.

9 A. V. Zmozinski, A. Jesus, G. R. Maria, M. G. R. Valea, and M. M. Silva: Talanta 83 (2010) 637.

10 F. G. Lepri, E. S. Chaves, M. A. Vieira, A. S. Ribeiro, A. J. Curtius, L. C. C. De Oliveira, and R. C. De Campos: Appl. Spectrosc. Rev. 46 (2011) 175.

11 E. S. Chaves, M. T. C. de Loos-Vollebregt, A. J. Curtius, and F. Vanhaecke: Spectrochim. Acta Part B: Atom Spectros. 66 (2011) 733.

12 J. R. De Souza, E. F. dos Santos, C. B. Duyck, and T. D. Saint'Pierre: Spectrochim. Acta Part B: Atom Spectros. 66 (2011) 356.

13 R. Sánchez, J. L. Todolí, C. P. Lienemann, and J. M. Mermet: Spectrochim. Acta Part B: 88 (2013) 104.

14 M. G. A. Korn, D. C. M. B. Santos, M. A. B. Guida, I. S. Barbosa, M. Passos, and J. L. F. C. Saraiva: J. Braz. Chem. Soc. 21 (2010) 2278.

15 E. J. Dos Santos, A. B. Herrmann, E. S. Chaves, W. W. D. Vechiatto, A. C. Schoemberger, V. L. A. Frescurab, and A. J. Curtius: J. Anal. At. Spectrom. 22 (2007) 1300. 
16 A. Y. Shishov, L. S. Nikolaeva, L. N. Moskvin, and A. V. Bulatov: Talanta 135 (2015) 133.

17 M. Barbagallo, G. Di Bella, V. Brucato, D. D’Angelo, P. Damiani, A. Monteverde, M. Belvedere, and L. J. Dominguez: Metab. Clin. and Exp. 63 (2014) 502.

18 F. H. Lyra, M. T. W. D Carneiro, G. P. Brandão, H. M. Pessoa, and E. V. de Castro: Microchem. J. 96 (2010) 180 .

19 A. R. Sadrolhosseini, A. S. M. Noor, and M. M. Moksin: Plasmonic_-Principles and Applications, Ed. K. Y. Kim (inTech, London, 2012) p. 253.

20 J. Homola, S. S. Yee, and G. Gauglitz: Sens. Actuators, B 54 (1999) 3.

21 R. B. M. Schasfoort and A. J. Tudos: Handbook of Surface Plasmon Resonance (RSC Publishing, London, 2008).

22 A. R. Sadrolhosseini, M. M. Moksin, W. M. M. Yunus, Z. A. Talib, and M. Abdi: Opt. Rev. 18 (2011) 331.

23 M. Abdi, L. C. Abdullah, A. R. Sadrolhosseini, W. M. M. Yunus, M. M. Moksin, and P. M. Tahir: PLoS ONE 6 (2011) e24578.

24 Y. Chervona, A. Arita, and M. Costa: Metallomics 4 (2012) 619.

25 K. K. Das, S. N. Das, and S. A. Dhundasi: Indian J. Med. Res. 128 (2008) 412.

26 H. M. El-Shafei: East. Mediterr. Health J. 17 (2011) 490.

27 S. E. Gurzau, C. Neagu, and A. E. Gurzaua: Ecotoxicol. Environ. Saf. 56 (2003) 190.

28 J. E. Garland, A. K. Assiongbon, C. M. Pettit, and D. Roy: Anal. Chim. Acta. 475 (2003) 47.

29 R. R. Dietert, J. E. Lee, I. Hussain, and M. Piepenbrink: Toxicol. Appl. Pharmacol. 198 (2004) 86.

30 A. R. Sadrolhosseini, M. Naseri, and S. A. Rashid: Opt. Laser Technol. 93 (2017) 216.

31 M. G. Naseri, E. B. Saion, H. A. Ahangar, M. Hashim, and A. H. Shaari: Powder Technol. 212 (2011) 80.

32 M. B. Shishehbore, A. Afkhami, and H. Bagheri: Chem. Cent. J. 5 (2011) 41.

33 A. R. Sadrolhosseini, A. S. M. Noor, M. Abdi, A. F. Abas, M. A. Mahdi, and Y. Al-Qazwini: Polym.-Plast. Technol. Eng. 53 (2014) 520.

34 A. R. Sadrolhosseini, M. Naseri, and H. M. Kamari: Opt. Commun. 383 (2017) 132.

35 E. Guibal: Sep. Purif. Technol. 38 (2004) 43.

36 A. Sugunan, C. Thanachayanont, J. Dutta, and J. G. Hilborn: Sci. Technol. Adv. Mater. 6 (2005) 335. 